\title{
Fast Food Consumption and Obesity
}

\author{
Nik Nairan Abdullah, Mazlin Mohamad Mokhtar, \\ Mohd Harriszamani Abu Bakar, Waqar Al-Kubaisy \\ Population Health \& Preventive Medicine, Faculty of Medicine, \\ Universiti Teknologi MARA, Sungai Buloh Campus, 47000 Sungai Buloh, Selangor, Malaysia \\ niknairan@yahoo.com
}

\begin{abstract}
This cross-sectional study investigated the pattern (frequency and characteristics) of fast food consumption and its relationship with obesity. A total of 1173 Malaysian adults were interviewed based on a structural questionnaire. Fast food consumption was higher among young Malays and significantly associated with age, ethnicity, number of children in the household. The prevalence of respondents who consumed fast food at least once a week was $17 \%$. Estimated $21.3 \%$ of respondents were obese. However, obesity was not associated with frequenting fast food restaurants. Because of the high prevalence of fast food consumption, there is a great need to educate further the community in making healthier food choices
\end{abstract}

Keywords: fast food,urban,obesity,consumption

eISSN: 2398-4279 @ 2017. The Authors. Published for AMER ABRA by e-International Publishing House, Ltd., UK. This is an open access article under the CC BY-NC-ND license (http://creativecommons.org/licenses/by-ncnd/4.0/). Peer-review under responsibility of AMER (Association of Malaysian Environment-Behaviour Researchers), ABRA (Association of Behavioural Researchers on Asians) and cE-Bs (Centre for EnvironmentBehaviour Studies), Faculty of Architecture, Planning \& Surveying, UniversitiTeknologi MARA, Malaysia.

https://doi.org/10.21834/ajqol.v2i6.42 


\subsection{Introduction}

Malaysia is continuously undergoing a rapid process of urbanization. Through the $9^{\text {th }}$ Malaysian plan, the government has taken the initiative to promote and encourage Western fast food franchises, as one of many efforts to boost the country's economy. Given this, 100 percent home delivery/takeaway outlets and cafes/bars/restaurants have seen the greatest growth, i.e. 61 to 97 percent from the year 2000 to 2005. Currently, there are five top U.S fast food establishment in the Malaysian industry; Kentucky Fried Chicken (KFC), McDonalds, Pizza Hut, Kenny Rogers Roasters and A\&W (Mohamed and Daud, 2012).

The pricing of fast food in Malaysia is very competitive, with continuous efforts from the food franchises to lower their prices to make it affordable to all walks of life. With escalating costs of living especially in urbanized cities, there is a tendency for people to opt for consuming cheaper-priced food. Some criticize fast food as "junk food" and believe that fast food promotion is a significant cause of the obesity epidemic in North America (Mohamed and Daud, 2012). Most fast food is laden with fat; combined with a lack of physical activities, it is a "recipe" for gaining unhealthy and excessive weight. Continuous consumption of fast food and sweet beverages will further increase the obesity risk of children (Alibabic et al., 2014).

\subsection{Literature Review}

Hectic lifestyle in urban cities has developed the habit of fast food consumption. Habib et al. (2011) documented that $84 \%$ of Malaysian university students' consumed fast food. Moore et al. (2009) found that his study participants in the lowest educational attainment and income categories were more exposed to fast food than those in the highest categories.

According to Astuti \& Hanan (2011), the preferences for dining places are influenced by the social class of people. This may also explain some studies found that younger groups were more exposed to fast food compared to those who were older (Anderson et al., 2011; Moore et al., 2009).Habib et al. (2011) documented that the growth of fast food is due to young adults who were likely to take their children to fast food eateries. There are several factors that may contribute to the increasing fast food consumption

Astuti \& Hanan (2011) also stressed that the atmosphere of the fast food outlets made it popular. In addition, Simovska- Anderson et al. (2011) stated that convenience was the predominant cause of frequenting fast food outlets. Jarevska et al. (2012) reported that price was one of the key determinants of customer satisfaction.

There is increasing concern over the types of food consumed (Din et al., 2012). In view of this, the government has advised fast food operators to provide nutritional information in its menu so that consumers are aware of the contents (Habib et al., 2011). Obesity was associated with the frequency of fast food consumption in the Anderson et al. (2011) study. 


\subsection{Methodology}

We conducted a cross-sectional survey in the month of April and May 2014. A total of 1173 people aged 12 to 65 years old who visited two health district clinics in Gombak, Selangor were included in the survey. Participants were selected using convenience sampling, as the aim is to gather as many data for the purpose of exploring fast food eating habits among this population. The inclusion criteria were; Malaysian, literate in Malay or English language, aged between 12 to 65 years old. Those who are non-Malaysian, patients on a wheelchair (not able to perform physical activity without an assistant) and those who are younger than 12 and above 65 years old are excluded from the study.

Consent was obtained verbally upon participants' agreement on their participation in the study. A self-administered questionnaire was used, and the participants directly interviewed by researchers to evaluate frequency and characteristics of fast food consumption. Prior of interviewing, an information sheet was provided to the participants. It contains details on the aims of the study and the purpose of the survey to be conducted and the contact numbers of the researchers involved in case of any queries they may have. Anthropometric measurements were also taken which included participants' weight and height.

This instrument was developed by current literature (Anderson et al., 2011; Moore et al., 2009), with the purpose to collect data that are more relevant towards Malaysian culture and habits. Weekly fast food consumption is defined as 'usually go to a fast food restaurant at least once or more times per week'. For obesity, we used the Malaysian Association for the study of obesity (2014) parameters. Body Mass Index (BMI) $18.5-24.9 \mathrm{~kg} / \mathrm{m} 2$ were considered normal weight, $25.0-29.9 \mathrm{~kg} / \mathrm{m} 2$ was overweight and BMI $\geq 30.0 \mathrm{~kg} / \mathrm{m} 2$ was obese.

Data obtained from this study was analyzed using descriptive statistic and chi-square. Additionally, we used univariate and multivariate logistics regression model for analysis to generate crude and adjusted odds ratios for trends and obesity. The analysis was done by SPSS software version 19.0.

\subsection{Results and Discussions}

A total of 1173 participants joined this study with an average age of $33.33 \pm 29.0$ years old; half were adults (588), about a third were young people (401), and about $16 \%$ (184) were older people. Almost two-thirds were female (59.5\%) and the majority were Malays (938), followed by Chinese (116), Indians (100), and others (19). Education wise, more than half had tertiary qualifications, and the rest had secondary education or less. Half of the participants were currently working and on average they had a household income of MYR $3634.30 \pm 3205.33$ per month, which is below the current mean ${ }^{1}$ for Malaysian households 
income as of the year 2014 (Chu, 2014). Over 60\% were married or previously married (728) with more than half, having at least one child (673). Very few stated their reason for choosing fast food was due to the price, even though it is considered cheap and affordable.

On average, participants were overweight with a BMI of $26.20 \pm 56.51$, with about a fifth of the sample being obese (246). Overall, the prevalence of respondents who consumed fast food at least once a week was $17 \%$ (200). However, most of them reported having fast food at least once a month (801). Younger participants were significantly found to be consuming fast food more frequently $(52.5 \%, p<0.001)$ than others. Our result was similar to other studies (Anderson et al., 2011; Moore et al., 2009) whereby younger groups were more exposed to fast food. This productive age group of working people consumed fast food more, as they have less time to cook at home.We found that taking children to the fast food restaurants was one of the influential factors. This is coherent with Habib et al. (2011) documentation that the growth of fast food is due to young adults who were likely to take their children to fast food eateries. More adults are eating away from home because they are working, and those with children have less time to cook at home.

Between the major ethnic groups, the Malays reported significantly higher prevalence $(86.8 \%, p=0.017)$ compared to the Chinese and the Indians. We were unable to provide explanations for the Malay predominance because of the study was explanatory. However, regarding fast food purchasing, Habib et al. (2011) found that Indians spend less due to their average income allowances being the lowest while Chinese spent the most. Thus, the price is regarded as one of the influential factors in purchasing fast food.

Individuals who did not have children were also reporting higher frequencies of fast food intake $(53.0 \%, p=0.001)$ compared to individuals who had children. Participants without children consumed fast food more frequently compared to those without any children.

For the younger population, either unmarried or married without children, it is considered reasonable for them to consume fast food. The probable reasons were that fast food was ready to be consumed, besides saving the trouble of cooking.In terms of socioeconomic factors, participants who had tertiary qualifications reported a significantly higher prevalence of fast food consumption $(64.5 \%, p<0.001)$ compared to those with secondary education or less. However, household income had no association with frequency of fast food intake among this population. In the multivariate regression model, the analysis showed that participants who were young people ( $<24$ years of age), of Malay ethnicity, and did not have children, were found to be significantly more likely to consume fast food on a weekly basis.

\section{Characteristics of fast food consumption}

The study further investigated the characteristics of frequent fast food consumers. It was found that participants reported 'sociability' (38.3\%) as the main reason for choosing to eat fast food at least once a month. Sociability was the main reason our sample chose to consume fast food. This might be influenced by the age characteristics of our study population, a majority of who were young people. 
We also discovered in this present study that most meals were purchased during dinner. Since most of our participants frequented the fast food restaurant with family members, this might be a means of socializing between members of the family.

Very few stated their reason for choosing fast food was due to the price, even though it is considered cheap and affordable. The second most common reason was quickness. Mirroring Ho Voo's (2011) study, he found that the impact of service was greater among fast food customers.

Usually, participants had fast foods for 'dinner' (53.6\%) and regularly ordered 'meal package' instead of 'set meal' ( $55.7 \%$ vs. $7.2 \%)$. These take-out fast foods were usually enjoyed at home $(87.7 \%)$, with most reporting having fast foods at the restaurants with their 'family' (63.0\%).

As for nutritional information, $48.0 \%$ acknowledged that the nutritional information was available to them, $84.2 \%$ have ever read about; $30.0 \%$ always have or most of the time used the information, and $68.6 \%$ indicated that they were very or somewhat likely to order 'healthier' food. Similarly, Anderson et al. (2011) also reported that only $16 \%$ ever used nutritional information when ordering, although hypothetically $68 \%$ of adults would choose healthier fast food items when available. Nevertheless, we are uncertain whether those who ever read truly understood the information. They reported 'ever read nutritional information' might be due to the increasing number of people being health-conscious and concerned over the types of food they consume (Din et al., 2012).

Among those who were obese, only $13.8 \%$ reported having fast food on a weekly basis and a half (50.8\%) reported monthly consumption (Table 1$)$. No significant differences were found for the multivariate among obese participants who consumed fast foods on weekly, monthly, less than once per month basis, and those who did not consume fast food at all. Our finding contradicted with the Anderson et al. (2011) study.

We acknowledge the potential of recalled bias experienced by the participants that may decrease the validity of our study findings. However, we sampled a wide range of age demographic, and this is one of the study's strengths. In addition, we investigated the pattern of fast food consumption, which was limited in local literature.

It is important to emphasize health education using the media (Simovska-Jarevska et al., 2012) since mass media is highly accessed by young people. There should be a radical change in the food market and food production, including the availability of wholesome foods and slowly eliminate the regularity of unhealthy fast food intake. There is a vital need to initiate an investigation on the long-term health effects of unhealthy fast food consumption within the Malaysian population.

\subsection{Conclusion}

The prevalence of respondents who consumed fast food at least once a week was $17.4 \%$. However, most of them reported having fast food at least once a month. On the other hand, 
younger age group, Malays, and did not have children, were found to be significantly more likely to consume fast food on a weekly basis. Malays consumed fast food more frequent than other ethnicities. The participants were generally overweight. Among those who were obese, only $13.8 \%$ reported having fast food on a weekly basis and half $(50.8 \%)$ reported monthly consumption. The frequency of consuming fast food was not significantly associated with obesity. The frequent consumption of fast food is rather alarming. The accessibility significantly influences the increased consumption. We also recommend that nutritional education should be given continuously to mothers, as it will, in turn, benefit all the family members.

\section{Acknowledgement}

We acknowledge Gombak Health district office for their assistance.

\section{References}

Alibabić, V., Mujić, I., Rudić, D., Golob, M., Šertović, E., Bajramović, M., \& Jokić, S. (2014). Assessment of Diet Quality and Nutritional Risks Representation of University of Bihać. Procedia-Social and Behavioral Sciences, 116, 2137-2140.

Anderson, B., Lyon-Callo, S., Fussman, C., Imes, G., \& Rafferty, A. P. (2011). Peer Reviewed: Fast Food Consumption and Obesity Among Michigan Adults. Preventing chronic disease, 8(4):A71.

Astuti, Sri., Hanan, Himasari.(2011). The behaviour of consumer society in consuming food at restaurants and cafes. Journal of Asian Behavioural Studies,1(1),73-81.

Boo, Ho Voon. (2011). Service environment of restaurants: findings from the youth customers. Journal of Asian Behavioural Studies,1(2),45-56

Chu, M.M. (2014).Malaysians are enjoying a better standard of living with the average household income surpassing RM5,900 a month. http://www.bernama.com.my. Accessed 8 September 2014.

Din, N., Zahari, M. S. M., \& Shariff, S. M. (2012). Customer Perception on Nutritional Information in Restaurant Menu. Procedia-Social and Behavioral Sciences, 42, 413-421.

Habib, F.Q., Dardak, R.A., Zakaria, S. (2011).Consumers' preference and consumption towards fast food: Evidences from Malaysia. Business Management Quarterly Review, 2(1),14-26.

Hwang, J., \& Lorenzen, C. L. (2008). Effective nutrition labelling of restaurant menu and pricing of healthy menu. Journal of Foodservice, 19(5), 270-276.

Malaysian Association for the study of obesity. Defining obesity.http:/www.maso.org.my/spom/chap3. pdf. Accessed 8 September 2014.

Mohamed, R. N., \& Daud, N. M. (2012). Cultural Uncertainty on Brand Trust of Fast Food Industry in Malaysia. Procedia-Social and Behavioral Sciences, 42, 399-412. 
Moore, L. V., Roux, A. V. D., Nettleton, J. A., Jacobs, D. R., \& Franco, M. (2009). Fast food Consumption, Diet Quality, and Neighborhood Exposure to Fast Food The Multi-Ethnic Study of Atherosclerosis. American Journal of Epidemiology,170(1), 29-36.

National Institute of Health, Ministry of Health (2012). National health and Morbidity Survey 2011. Fact sheet. http://www.moh.gov.my, Accessed 8 September 2014.

Othman,C.N.,Che Lamin,R.Z.,Farooqui,M.,sihab,N.,Mohd Said,S.(2012), Journal of Asian Behavioural Studies,2(7),37-46 